\title{
Characteristics of the Monographic Literature of British and American Literary Studies
}

John Cullars

The aim of this study was to determine how scholars use the monographic literature in British and American literary studies and to compare these findings to those of studies involving the journal literature of the humanities. All references were counted from thirty monographs, including implicit references not formally cited. The findings of this study were in agreement with most similar studies of the journal literature of the humanities with one important exception. While book references constitute the most important source of scholarship and most references were more than ten years old but published since the Second World War, as with the journal literature, manuscript references play a much greater role, sometimes exceeding that of journal references.

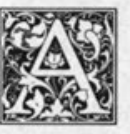

review of the library literature shows an increasing recent interest in the patterns of citation and reference for the humanities literature. Though most of these studies follow the lead of earlier work in the sciences and social sciences, there were isolated studies of humanities citation patterns in the literature as early as 1959 and 1960. Librarians have sought to understand which sources are most used by researchers so as to be able to supply those items in times of budgetary crisis when cuts in acquisitions have been inevitable; scholars over the past fifteen years have adopted or adapted such techniques from the sciences and social sciences as citation studies to gain a clearer, less subjective view of what materials function as core collections for the various disciplines.

These studies, while using the methodology developed in the sciences and social sciences, have found significant differences between the use of the journal litera- ture in the sciences and social sciences and that of the humanities. The collection and evaluation of data determining which books, journal articles, manuscripts, and dissertations have been cited by scholars in their work and the currency of these materials have been used for both theoretical and more controversially practical ends. As well as providing a means to augment the researcher's knowledge of the shape of a discipline's literature, administrators have used this data in promotion and tenure decisions, and librarians have used it in the development of collection development guidelines.

Citation studies can be performed by a single individual in a relatively short time without disrupting any library or faculty activities, but the greatest advantage has been thus described by Stephen Wiberley:

Probably most important for an academic librarian is the fact that a citation is a component of the most important product of the academic enterprise, a scholarly publication. In their best

John Cullars is bibliographer for the humanities at University of Illinois, Chicago, Illinois 60680. He expresses his appreciation to his colleagues Stephen Wiberley and Elizabeth McCartney for their encouragement and help with the manuscript of this study. 
form scholarly publications are those which appear as sources edited and refereed by experts in a field, but they may also include any publication written with the aim of becoming part of the literature on a subject. As such they normally contain citations to other publications that have helped to shape an author's writing, whether by summarizing previous work on a subject, offering references to supportive or opposing conclusions, providing evidence, suggesting methodology or explaining analogous topics. Citations show where an author's work fits into the literature on a subject. ${ }^{1}$

Though such scholars as M. B. Line accept the value of citation studies in determining the shape of the literature but are highly skeptical of their validity and precision as evaluative tools for collection building and weeding in individual libraries, many researchers continue to find them satisfactory guides to the evaluation of use patterns, particularly when taken in conjunction with such other quantitative tools as user surveys, circulation studies, and surveys of in-house use, as well as such qualitative guides as lists compiled by recognized experts in the field.

Humanities scholars had long warned that the subjective evaluation of the nature of humanistic research and publication suggested major differences between their use of the literature and that of their colleagues in the sciences and social sciences. Various studies have borne out these assumptions to a great extent so far as the journal literature in the humanities is concerned. Less has thus far been attempted toward evaluating the uses of sources in the monographic literature of the humanities; this study makes a necessarily limited step in that direction, seeking to verify or cast doubt upon the applicability of findings concerning the humanities journal literature to that of the monographic literature.

Humanities scholars claim that (1) the book is paramount in their research rather than the journal article that serves as the basis for scientific and social scientific research; (2) older sources, both primary and secondary, continue to be cited to a vastly greater degree than in the sciences and social sciences; and (3) foreign language sources in the humanities are far from negligible. All these assumptions have been substantiated by recent studies of the journal literature in the humanities and in the library literature. Although there is no claim to statistical validity due to a limited sample size, this study seeks to isolate tendencies in the monographic literature of English and American literary studies published between 1976 and 1983; tendencies as to the proportion of references in monographs to books, to journal articles, to manuscripts and to dissertations, as well as to the chronological spread of these references. Comparisons will be made to similar studies of the journal literature in the humanities for purposes of comparison and contrast. Since this study limits itself to English language materials dealing with English-language literary topics, the question of the citation of foreign-language material must await another study.

\section{LITERATURE REVIEW}

The genesis of this study was Madeleine Stern's article "Characteristics of the Literature of Literary Scholarship," which explored citation patterns in the journal literature of English and American literary scholarship between 1976 and 1980. Basing her findings on data provided by the Arts and Humanities Citation Index (AHCI), Stern found that citations to monographs far exceed those to journal articles, as opposed to citation practice in the sciences and social sciences where references to the journal literature significantly predominate. She also found that a number of citations in English and American studies are to older publications than is the case with the sciences and social sciences, although the greatest number of citations is published within twenty years of the citing article. For important pre-twentieth century writers, more than 40 percent of all citations were to material published before 1900 . Finally, she reported that references to manuscripts and dissertations were negligible.

Given the emphasis that humanities scholars place on books, it is useful to investigate reference patterns in this monographic literature using Stern's findings on the journal literature for comparison 
and contrast as well as data drawn from the citation studies in other humanistic fields: Baker in musicology, Heinzkill in English, Longyear in musicology, Simonton in the fine arts, and Vaughan in musicology. This study seeks to discover to what extent citation patterns in the monographic literature coincide with or deviate from the patterns discovered in these studies of the journal literature. Do books play a comparably major role? Are manuscripts and dissertations equally ignored? Do patterns of use across time hold and in the same proportions for the monographic literature as for the journal literature?

\section{METHODOLOGY}

While this study duplicates the principal aims of Stern's study of the journal literature of English and American literary scholarship, the methodology differs and the scope of the findings is more modest. Stern drew all her data from the $A H C I$, including even implicit citations from the text that were not officially footnoted but were located and tabulated by the staff of ISI. This tool allowed her to examine a sufficiently large sample to yield statistically valid projections. $A H C I$ analyzes only journal articles and collections of essays, not monographs.

To do a comparable study of the reference patterns in the monographic literature, the researcher had to examine personally all of the books surveyed, tabulating the entries from footnotes and endnotes as well as skimming each page for implicit citations. Since the currency of references is a point to be investigated, and scholars frequently quote or refer to well-known passages from the Bible or classic authors without formally citing them, such a search for implicit citations was necessary to arrive at any accurate tabulation of the total number of references involved. In some cases, such unfootnoted references did seem ornamental rather than substantive, but in many more cases, a citation from a classic author or a well-known older critic was used to corroborate a point or as a springboard for further discussion. While the opinion of a currently active critic or scholar was almost invariably cited formally, compara- ble passages from classic works or famous pre-twentieth century critics, while identified in the text, often were not felt to require formal citation. It cannot be claimed that all such implicit citations have been identified in this study since the books were skimmed rather than read, but all pages were examined. For this study, evoking an author's name did not qualify as a reference unless an idea, theory, or quotation was connected with that name in the text.

Technically this is a reference study rather than a citation study; each appearance of a given text is noted rather than the single citation of a given title regardless of how frequently the author refers to it. The researcher decided to tabulate all references to a given work rather than just the first citation to it because he considered that methodology more apt to document fully the scholarly practice in humanities monographs. In a journal article, individual sources are less likely to yield multiple references than in full-length monographic studies in which different aspects of a source may be drawn upon repeatedly. Standard editions of literary texts, collections of letters, manuscript collections, and authorized or otherwise standard biographies, which are basic to most humanities scholarship, are less important in scientific and some social scientific research in which the scholars concentrate primarily upon experimental or survey data. Thus counting a repeatedly used source as a single citation rather than counting each use would underestimate the value of certain sources. It would also tend to minimize differences between the patterns of humanities and scientific/social scientific use patterns that might otherwise emerge. In tabulating the chronological spread of references, those sources that are repeatedly cited obviously weight the decade in which they appear in terms of percentages of references by decade or other chronological spans. These different emphases between reference studies and citation studies cause the limitation that the comparison of this study's findings to a lesser or greater extent may not be strictly comparable to those of citation studies. Thus similarities and dissimilari- 
ties found and discussed could be misleading.

While this study did not consistently and systematically differentiate between primary and secondary sources in the tabulation of references, single sources that were repeatedly cited were counted separately. Six of the non-prizewinners and four of the prizewinners required such separate treatment though only two monographs from each group contained notably large numbers of such primary source citations. The largest number of such references was 522 out of a total of 1,712 . Collected letters as well as literary texts made up these primary sources. In this study, non-prizewinning studies of twentieth century authors made the strongest use of primary sources. Older topics depended less heavily upon them in both groups of books. A truly systematic study of the citation patterns regarding primary and secondary sources in the humanities could show whether secondary sources in the humanities continue to be cited for a significantly longer period than in the social sciences. It is possible that the continued citation of primary literary texts amounts for the bulk of such older references, but this study does not suggest that to be true.

Two samples of monographs were examined: (1) fifteen prizewinning books published between 1976 and 1983 located in the yearly lists of prizewinning books in Publishers Weekly; and (2) fifteen books drawn from the Dewey categories represented by the prizewinning books randomly selected from the pertinent yearly volumes of American Book Publishing Record. While it is not possible to be certain that none of the latter won any prizes whatsoever none won any of those prizes covered by Publishers Weekly. To qualify for inclusion a book had to contain footnotes or endnotes, but a formal bibliography was not required. Textbooks or collections of essays were also excluded. While these stipulations did not eliminate any of the prizewinning items, approximately every third randomly selected non-prize book was eliminated for lack of scholarly apparatus.

To select the non-prizewinners, the
Dewey cases of all the prizewinners were ascertained and, within each yearly volume, the pertinent pages were renumbered to include all relevant categories in a consecutive numerical sequence. Two random numbers were chosen separately from a random-numbers table, one for page number and the second for the position of the item on the page. If a chosen book had to be rejected as out of scope, the next book on the list that fit the criteria was chosen. The labor-intensive nature of this methodology and the individual examination of each book has limited the number of monographs selected to thirty in all.

The study sought to discover if there would be any significantly different reference patterns between prizewinning and non-prizewinning monographs in the same areas of research published at the same time.

Since it was clearly impossible to consult enough books to produce statistically significant data, this study only seeks to isolate tendencies in the reference patterns of the monographic literature of English and American literary scholarship of the period from 1976 to 1983 that may be the basis for further investigation. This discipline and span of years has been chosen so that the findings of this study may be most comparable to Stern's for the journal literature of the same field and period. References were also tabulated by the decade in which they appeared so that their chronological distribution could be compared to the findings concerning the journal literature of the humanities and social sciences. Table 1 lists the number of references, explicit and implicit, divided into prize and non-prizewinning books.

The length of monographs ranged from 132 to 561 pages with a median length of 236 pages for non-prizewinning books and from 170 to 874 pages with a median length of 454 pages for prizewinners. References per page ranged from .8 per page to 2.9 per page with the median 1.8 references per page for non-prizewinners and from .8 per page to 4.9 per page with the median 2.4 references per page for prizewinners. Nine of fifteen prizewinners had two or more references per page whereas only six non-prizewinners did. The total 
TABLE 1

NUMBER OF REFERENCES PER BOOK

\begin{tabular}{|c|c|}
\hline Prize Books & Non-Prize Books \\
\hline $\begin{array}{l}\text { 1. } 239 \\
\text { 2. } 255(3 ; 1.2 \%)^{\star} \\
\text { 3. } 528 \\
\text { 4. } 674 \\
\text { 5. } 707 \\
\text { 6. } 728(136 ; 18.7 \%)^{\star} \\
\text { 7. } 848 \\
\text { 8. } 899(472 ; 52.5 \%)^{\star} \\
\text { 9. } 1,000 \\
\text { 10. } 1,148(29 ; 2.5 \%)^{\star} \\
\text { 11. } 1,168(66 ; 5.7 \%)^{\star} \\
\text { 12. } 1,712 \\
\text { 13. } 1,854 \\
\text { 14. } 2,005 \\
\text { 15. } 2,070\end{array}$ & $\begin{array}{l}94(52 ; 55.3 \%)^{\star} \\
163 \\
175(3 ; 1.7 \%)^{\star} \\
204(1 ; .5 \%)^{\star} \\
276 \\
281 \\
415(15 ; 3.6 \%)^{\star} \\
444 \\
445(297 ; 66.7 \%)^{\star} \\
474 \\
479 \\
501 \\
606 \\
862 \\
883(45 ; 5.1 \%)^{\star} \\
\end{array}$ \\
\hline 15,838 & $\overline{6,302}$ \\
\hline
\end{tabular}

-Asterisk indicates that the figures in parenthesis show implicit references, first the number of such implicit references and then their percentage of the whole for that book.

number of references for prize books was more than 2.5 times greater than that for the non-prizewinning books. As can be seen, no prizewinning book had fewer than 239 , but seven had fewer than 1,000 references, while no non-prize book had over 883. One non-prize book had as few as 42 explicit references with, however, another 52 implicit references. Seven of the prize books had more references than the highest number held by a non-prize book. Both groups were about equally prone to implicit citations.

Only two of the prizewinning books approached the non-prize books in terms of brevity of text and paucity of references whereas only one of the non-prize books approximated the length of most prize books but had fewer references than a prize book of comparable size would have had. Roughly one-third of the non-prize monographs were clearly intended as introductory studies of famous writers, though not as textbooks per se, whereas none of the prize books were of an introductory character.

\section{RESULTS}

These results present the data collected in this project by two different approaches: (1) the percentage of references to the form of source (book, article, manuscript, dissertation) and (2) by the chrono- logical period in which the citation appeared. Where a further breakdown seemed informative, data will be subdivided into prize, non-prize, and the total number of books. In this tally, a reference to an article within a collection of essays is treated as a book citation since the scholar cited it in that form even though it may have appeared previously as a journal article. Newspapers, magazines, and conference proceedings are considered as articles. If an author cites a reprint edition, the reprint date is taken. When an author gave extensive bibliographical information in footnotes rather than simple bibliographical citations, if the additional references seemed supplementary, they were excluded; if the author demonstrably had made substantive use of them, they were included. While a subjective element of judgment enters into such decisions, only three of thirty books studied presented such problems. Explanatory or interpretive footnotes were not considered unless they also contained bibliographical references germane to the text. Printed interviews are treated as articles; typescript or taped interviews or notes based on direct or telephone conversations are classed as manuscripts.

In providing tallies of percentages of references by chronological periods, these percentages equal less than 100 percent because most implicit citations could not be assigned to a given decade since they were usually references to material that by its classic nature exists in a wide variety of editions. In two cases, both non-prize books, implicit citations exceed 50 percent of the total. One was a discussion of Shakespearean staging that quoted copiously from the poet's works but never indicated the edition. Indeed, if this author was quoting directly from the numerous different productions discussed, many different editions were surely represented.

Table 2 presents two different approaches to reference patterns in the monographic literature. In the left half of each rectangle, the percentage is based on the portion of references to a given type of source (book, article, manuscript, dissertation) divided by the total number of ref- 
TABLE 2

\section{PERCENTAGE OF REFERENCES*}

\begin{tabular}{lccc}
\hline \hline & $\begin{array}{c}\text { Prize Books } \\
\text { (15,838 References) }\end{array}$ & $\begin{array}{c}\text { Non-Prize Books } \\
\text { (6,302 References) }\end{array}$ & $\begin{array}{c}\text { Total Books } \\
\text { (22,140 References) }\end{array}$ \\
\hline Books & $62.2 \% / 65.6 \%$ & $74.5 \% / 78.8 \%$ & $65.7 \% / 72.2 \%$ \\
Articles & $12.7 \% / 13.8 \%$ & $14.8 \% / 15.3 \%$ & $13.3 \% / 14.5 \%$ \\
Manuscripts & $24.8 \% / 20.3 \%$ & $10.4 \%+/ 5.6 \%+$ & $20.7 \%+112.9 \% \dagger$ \\
Dissertations & $.26 \% / .25 \%$ & $.36 \% / .6 \%$ & $.29 \% / .29 \%$ \\
\hline
\end{tabular}

*The figure on the left of the slash gives the percentage of references based on the total number of references; the figure on the right gives those percentages based on the averages of the individual percentages of each type of source divided by 15 for each sample group and by 30 for the total.

tOne non-prize book uncharacteristically had manuscript references far outweighing all other categories (63.5\%). It was the only non-prize book with as many as $12.5 \%$ manuscript references. Omitting this book from the tabulations gives figures in columns 2 and 3 of $1.8 \% / 1.4 \%$ and $18.9 \% / 10.8 \%$ respectively.

erences for the prize books $(15,838)$, nonprize books $(6,302)$ and the total combined sample group $(22,140)$. Thus, to take 62.2 percent for prize books, all the references $(9,851)$ to books in the sample of fifteen prize books was divided by 15,838 , the total number of references to all forms in the prize book sample.

In the right half of each rectangle of table 2 , on the other hand, the percentage of references to each type of source is based on the addition of the individual averages for each book in a given type of source (book, article, manuscript, dissertation) divided by fifteen, the total number of books in each separate group, or by thirty for the percentage for the total group of thirty books. Thus, the 65.6 percent figure for prize books was arrived at by taking the percentage of references to books for each prize book, adding them up, and dividing by fifteen since there were fifteen prize books. This technique gives equal weight to each book as a representative of scholarly practice.

Since these figures do differ to a notable degree on occasion, both percentages have been provided in the table. It should also be noted that the presence of one non-prize book with an atypically high number of manuscript references (561 out of a total of $883,63.5$ percent) has perhaps misleadingly elevated the manuscript percentage for both non-prize and the total percentages. The figures given in the notes to table 2 give these manuscript percentages minus this book, and these adjusted percentages are perhaps more reliable.

Figure 1 and table 3 reflect the chrono- logical spread of the topics of these thirty monographs. Of the thirty books, fourteen dealt exclusively with the twentieth century, two exclusively with the nineteenth, two exclusively with the eighteenth, and six fell between the fifteenth and seventeenth centuries with much overlap. In addition, seven books dealing with more recent topics also showed a broad overlap between centuries, as with a book on Shakespearean staging between the seventeenth and twentieth centuries. Discrepancies between the figures cited above and those in the totals of figure 1 are explained by the arbitrary assigning of books that overlap to a given century for the tally. Though no book's topic predated Chaucer (c. 1340-1400), there were numerous references to much earlier literature, particularly the Bible and classical antiquity. Thus the references ran the gamut from Heraclitus (c. 500 B.c.) to 1980. The chronological distribution is indicated in four categories with 1980 the terminal date since no later references appeared in these books. Three thirty-year periods (1950-80, 1920-50, and 1890-1920) accounted for the bulk of the references with a final "pre-1890" category to account for the remainder.

\section{DISCUSSION}

In observing the results of table 2, one sees that, as in previous research into the citation of journal articles in the humanities by Baker, Heinzkill, Simonton, Stern, and Stone, references to monographs strongly predominate over any other type of source material as opposed to the stronger reliance on the journal literature 


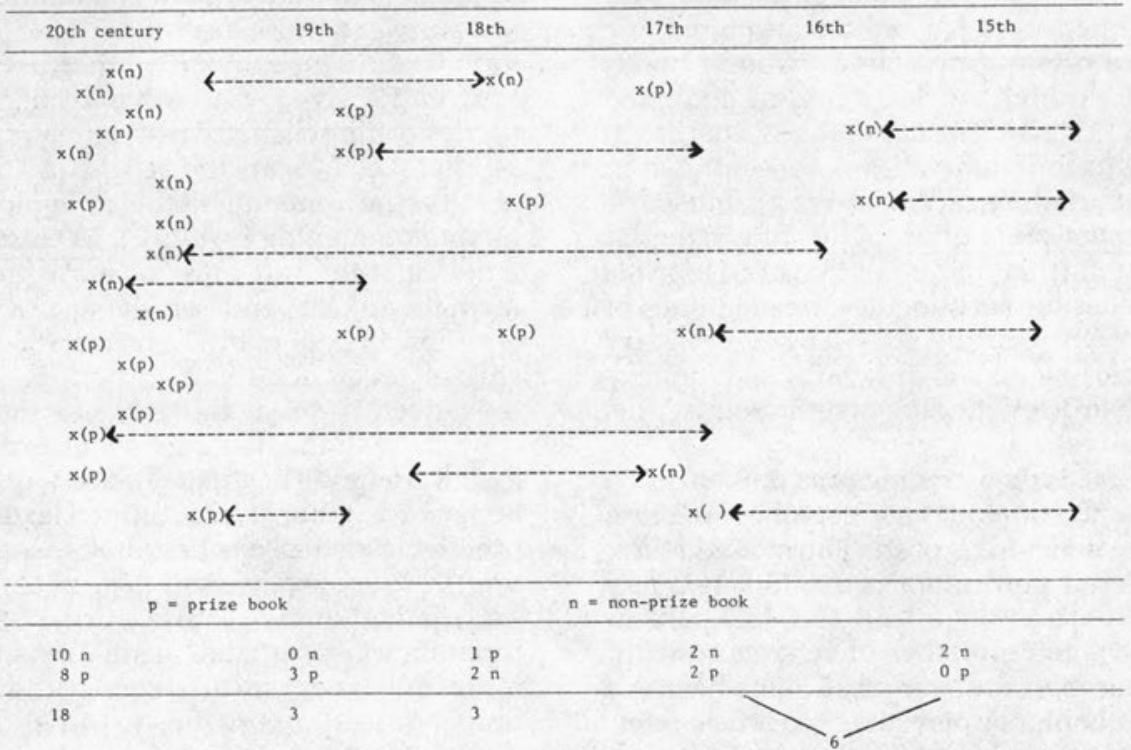

Note: Tallies by century include books that overlap centuries.

FIGURE 1

Distribution of Topics by Century

TABLE 3

TEMPORAL PERCENTAGES

\begin{tabular}{lccc}
\hline \hline & Prize Books & Non-Prize Books & Total Books \\
\hline $1950-80$ & $54.1 \%$ & $67.7 \%$ & $61.7 \%$ \\
& $(17.1 \%-91.4 \%)$ & $(16.7 \%-99.4 \%)$ & $(17.1 \%-99.4 \%)$ \\
$1920-50$ & $24.1 \%$ & $15.2 \%$ & $20.5 \%$ \\
& $(5.3 \%-51.8 \%)$ & $(.2 \%-62.4 \%)$ & $(.2 \%-62.4 \%)$ \\
$1890-1920$ & $8.9 \%$ & $6.9 \%$ & $8.4 \%$ \\
& $(.1 \%-24.6 \%)$ & $(.2 \%-17 \%)$ & $(.1 \%-19.4 \%)$ \\
Pre-1890 & $12.1 \%$ & $5.5 \%$ & $9.1 \%$ \\
& $(.1 \%-46 \%)$ & $(.2 \%-37.5 \%)$ & $(.1 \%-46 \%)$ \\
\hline
\end{tabular}

The percentages in parentheses under each figure show the range in each category of book for which the average is shown.

typical of the sciences and social sciences. Whether considering the total $(72.2 / 65.7$ percent), prize books (65.6/62.2 percent) or non-prize books (78.8/74.5 percent) percentages, well over 50 percent of all references are to books, with the non-prize book percentages notably higher than prize books. This may be compared to 82.7 percent for authors and 78.8 percent for literary movements in Stern's study; ${ }^{3} 75$ percent in Heinzkill's study of English literature; ${ }^{4}$ Simonton's 71.5 percent for fine arts; ${ }^{5}$ and Vaughan's 69.5 percent for mu- sicology. ${ }^{6}$ Scholarly attitudes implied in the evaluative literature of the humanities indicate that these scholars still regard their magna opera as the definitive monographs in the field, and in numerous universities, promotion to full professor requires the publication of highly regarded monographs as well as articles. Stern found that book reviews play a very prominent role in the journal literature of the humanities as examined by $A H C I$, a further reflection of the importance of monographs in the scholarly enterprise of the 
humanities. She also found that pretwentieth century authors and topics are more often approached through books than through articles, a finding seconded by this study. The use of the journal literature in the humanities is concentrated in the period since World War II but more than ten years prior to the study citing it. Stern further points out that even reprints of older primary sources, new editions of great authors, and book-length secondary studies by prominent critics take priority over articles, findings confirmed by this study as well.

This study's findings on references to journal articles also corresponded to those of earlier studies of the journal literature, 13.8/12.7 percent for prize, $15.3 / 14.8$ percent for non-prize, and 14.4/13.3 percent for the total number of references with, once again, the non-prize items having a slightly higher percentage to article references. Stern found 15.1 percent citations to articles in the journal literature dealing with authors and 16.5 percent for that dealing with movements. Simonton, on the other hand, found 28.6 percent references to articles; Heinzkill, 19.9 percent references to articles in English, and Vaughan 25.3 percent to articles in musicology. This study's findings tally closely with Stern's in the same discipline, while certain other disciplines within the humanities such as fine arts and musicology, while equally strong on book citations, contain twice as many references to the journal literature, documenting considerable variation in the use of the journal literature in the humanities.

As in the literature of the sciences and social sciences, more recent figures and topics are apt to be covered in the journal literature before extensive monographic coverage accumulates. Until recently, for instance, it was difficult to find monographic or reference-book treatment of Derrida's "deconstruction" theory, leaving the researcher no recourse other than journals. Now that monographs are appearing on this topic, it will be interesting to see if the proportion of journal citations to articles on deconstructionism decrease relative to those to monographs.

The most significant difference in the findings of this study of the monographic literature and those dealing with the journal literature concerns manuscript sources. Received wisdom has it that manuscripts (unpublished drafts, letters, typescripts, sketches) are the delight and daily bread of the humanities scholar. Typical of many commentators, Karl J. Weintraub writes that the humanist's "most fundamental work depends on the availability of original texts; many humanists have a special reverence for manuscripts, and they need the real thing rather than a copy. . . . Humanists care about texts in their varieties. They usually need all editions of a text, not just the printed texts but preferably also all the first drafts, second drafts, galley proofs, and page proofs."' Yet citation studies of the journal literature uniformly find that manuscripts rep-a resent only a very small fraction of the citations. Indeed, even those studies that combine manuscript and dissertation citations in the same category still offer minimal evidence of the use of such sources by humanities scholars. Thus textual scholarship appears to occupy a less exalted position in the humanities scholarship than is commonly supposed.

Stern found only 2.2 percent citations to manuscripts and theses for authors and 4.6 percent for literary movements, and her "other" category included encyclopedias as well as manuscripts and theses. Jones, et. al., on the other hand, found 12.6 percent citations to unpublished materials in their study of history, ${ }^{8}$ a social science held by some scholars to be more closely related to the humanities than any other. In musicology, Baker found 12.6 percent citations to unpublished materials, but most of these were to otherwise unavailable musical manuscripts written before 1800 . $^{9}$ Of this 12.6 percent, only 2.09 percent applied to manuscript letters and other non-score items. Vaughan found only 5.2 percent of his citations to non-published sources in his study. Given such low percentages of citation to manuscripts, researchers such as Stone have questioned the validity of the widespread assumption that manuscript sources are as vital to humanities research as most scholars claim. Stern, however, 
suggested that it might be the case that "research into the topic of an article is done in a less in-depth manner than if the published study were a full-length book. I suspect that analysis of citations in source monographs dealing with the same subject would yield a higher percentage of unpublished primary source citations." This study has indeed found Stern's assumption to be accurate. The figures concerning references to manuscripts were $24.8 / 20.3$ percent for prize books, $10.4 / 5.6$ percent for non-prize books, and 20.7/12.9 percent for the total, significantly higher figures than in any of the studies of the humanities journal literature. Even the subtraction from the tally of the one non-prize book whose manuscript references were uncharacteristically high left the total figure at $18.9 / 10.8$ percent.

While manuscript sources were more fully used by prize books than by nonprize books, there were significant manuscript references in both groups. Seven of the non-prize books but only two of the prize books omitted references to manuscripts altogether. As can be seen from table 2, manuscript references exceeded journal article references for prize books and for the combined sample as reckoned by the total number of references, though not by the average of the individual books. One of the non-prize books had 63.5 percent of all its references to manuscripts, and three of the prize books had manuscript percentages in excess of 50 percent to 53.6 percent, 58.9 percent, and 72.4 percent, as well as one just under, with 47.1 percent. Another had 33.1 percent manuscript references as opposed to 48.7 percent book and 18.2 percent articles references. Except for the one 63.5 percent manuscript percentage already mentioned, no non-prize book had more than 12.5 percent references to manuscripts while six prize books exceeded this. This study includes all references to manuscripts that are enumerated by the authors in their notes. In one case, however, an author merely listed twenty-two manuscript collections without any further breakdown of the manuscript sources consulted. Since this is a reference rather than a citation study, and thus all references are included insofar as they can be ascertained, this one book's failure to enumerate all its manuscript references suggests that the total use of manuscripts in this study was actually higher than shown by the findings.

This study does, however, corroborate all the studies of the journal literature in finding references to dissertations and theses to be negligible. There were no references to M.A. theses at all, and only $.26 / .25$ percent references to dissertations in prize books, $.36 / .6$ percent in non-prize books, and $.29 / .29$ percent in the total. The total number of references to dissertations was only 64 out of 22,140 total references, 41 in the prize books and 23 in the nonprize. Only a single author cited as many as three dissertations in his work. Eleven of the non-prize books and seven of the prize books contained no citations to dissertations at all. Only 1 percent of the materials cited in Baker's study were theses. Most of the studies of the journal literature of the humanities group dissertation citations with manuscript citations, so that it is impossible to offer figures for comparison in these cases. In areas in which published scholarship may be minimal or felt by the researcher to be inadequate, scholars may turn to dissertations for lack of other sources. Thus Brian Harrison in a review of a recent book on feminist theory states that the author Jane Lewis made "good use of recently completed doctoral theses" $" 11$ among a wide range of sources, but such would seem the exception, and no such exceptions were encountered in this study. Many libraries have a policy (or at least a strong disinclination) against purchasing dissertations, considering that the more worthy will be reworked into monographs in these "publish or perish" days. Dissertations are not always available through interlibrary loan and are relatively expensive to buy.

Figure 1 and table 3 display the chronological range of the references. Figure 1 shows that half the topics of these studies are centered in, if not confined to, the twentieth century while one-third of the books overlap centuries, having such broad topics as the English ode. Of course, 
strictly twentieth-century topics can and do contain references to earlier authors for a wide variety of reasons. Over 50 percent of the books ( 10 non-prize and 8 prize, including overlap) cover twentieth-century topics; the chronological distribution suggests no pattern of differences between prize and non-prize books. The importance of older sources is also much greater for the journal literature of the humanities than for that of the sciences or social sciences. This study also supports that finding for the monographic literature of the humanities. Whereas Garfield found that less than 40 percent was cited in the sciences more than five years old, he found that 62 percent of the citations in the journal History were older. ${ }^{12}$ Heinzkill found over 70 percent of his book citations for English literature were over ten years old, though 54 percent of these were published since 1945, thus dating between 1945 and 1970. Garfield found that, of the one hundred most cited scientists between 1961 and 1976, the oldest was born in 1899, whereas in a survey of one hundred humanists in 1977-78, 60 percent were born prior to 1900 and 10 percent prior to 1400 .

Stern found that the work of earlier humanists is not superseded nearly so rapidly as in the sciences and social sciences; Garfield stated that in the sciences even a classic paper frequently ceased to be directly cited after five years, that knowledge having been assimilated into the collective consciousness of the discipline, is "packed down" or "squeezed out," in Derek DeSolla Price's formulations. ${ }^{13}$ Longyear points out, on the other hand, that in musicology some articles continue to be cited more than seventy years after initial publication. As with the various findings for the journal literature of the humanities, the greatest concentration of references in this study of the monographic literature falls within the period 1950 to $1980,54.1$ percent for prize books, 67.7 percent for non-prize books, and 61.7 percent for the combined total. As can be seen, percentages ranged from 16.7 percent up to 99.4 percent of all references in this period. There were fourteen books on exclusively twentieth-century topics, one of them on the poetry of the 1960 s, so that a concentration of references in the latter half of the century was to be expected, but, less predictably, all books on pretwentieth-century topics also illustrated this pattern of citing recent scholarship. Thus 42.2 percent of the references in the books on nineteenth-century subjects, 53.6 percent of the eighteenth-century topics, and 64.9 percent of the books dealing with the fourteenth- to seventeenthcentury topics occurred in this recent period. Perhaps one reason for this is the lesser use of journal articles and the greater dependence on books for the investigation of older topics, with recent books and articles being preferred over all but classic older scholarship in most cases. The percentages of references decline progressively in the periods between 1920 and 1950 and between 1890 and 1920 . In the pre-1890 period, however, the exhaustive scholarship of three of the prize books with older topics gives a higher percentage of references to this category than to the 1890-1920 period except for the non-prize books, which, however, have a total only 1.4 percent lower. Some of these prize books had references from every single decade between 1690 and 1980! Significantly these works of exhaustive scholarship also cite manuscripts most fully and even make some limited use of dissertations.

In these studies, the most cited recent decade is $1960-70$ or $1950-60$ rather than 1970-80. This might bear out the findings in the journal literature of the humanities that most citation is to material over a decade old, but it might only reflect the fact that those books published in 1976-78 would not have the same opportunity to examine later scholarship as those published between 1979 and 1981. Of this sample of thirty books, nineteen were published between 1976 and 1979. 25.2 percent of the references of the prize books, 19.4 percent of the references of non-prize books, and 22.3 percent of the references of the total number of books fall between 1970 and 1980 as opposed to 31.7 percent for non-prize, 19.1 percent for prize books, and 25.4 percent for the total between 1960-70. Thus the findings for the studies of the humanities journal liter- 
ature that material ten or more years old is more heavily cited than materials more recently published hold true for the monographic literature as well, though the publication dates of many of these books made it impossible for them to have access to materials published throughout the latter part of the 1970s. This may exaggerate the preponderance of studies in the next most recent decade, 1960-70.

Major factors in the explosion of humanistic scholarship since 1945 have been discussed by Charles Osburn. ${ }^{14}$ Federal funding from such agencies as the Fulbright-Hays Program, the National Endowment for the Humanities, and the American Council of Learned Societies has further promoted the " publish or perish" atmosphere of contemporary American universities with competition for the funds and prestige associated with grants. Humanistic scholarship has also experienced important changes in both aims and methodology in the past four decades. They influence of social science disciplines, particularly psychology, anthropology, economics, and sociology, has greatly widened the scope of humanistic research and publication both theoretically and practically in terms of quantitative methods. The traditional reliance of humanities scholars on the received wisdom of past generations of scholars, the veneration of erudition for its own sake, and the almost exclusive use of conventional bibliographic and critical methods have been gradually replaced or supplemented by greater emphasis on creativity, originality, and the more objective investigation of man as a social animal or metaphysical being. Computer technology, particularly concerning linguistics and semiotics, has also played a role of increasing impact since the 1960 s.

\section{SUMMARY}

A study of thirty books can do no more than compare itself to earlier work and suggest tendencies that may be corroborated or challenged by further work. The findings of this study do coincide in most respects with those of previous studies of the journal literature of the humanities with one significant exception. As in those studies, books represent the predominant tool for humanities scholarship as opposed to journals that dominate the sciences and, to a lesser extent, the social sciences. Books are the major source for research about both the most recent literary trends and about pre-twentiethcentury works. The most significant use of journal articles is found principally in the period after World War II, though some seminal articles continue to be cited for seventy years or more in some disciplines of the humanities. For the older topics, however, the monographic literature is more apt to be supplemented by manuscript sources than by journal articles. The main difference between the citation patterns in the journal literature and the reference patterns of the monographic literature of the humanities is the much greater use of manuscript sources in the latter. Indeed, for prize books and the combined total of books, though not for non-prize books, manuscript references exceed those to journal articles. The use of dissertations and theses is negligible in both the monographic and periodical literature. In chronological terms, the largest concentration of references falls between 1950 and 1970. This study's results coincide with those of the journal studies in that the greater number of citations in the humanities were over ten years old. Despite the strong citation pattern to the $1960-80$ period, 52.3 percent of the references were older, and the pre-twentieth-century subjects regularly referred to books and/or manuscripts as well as to occasional journal articles from earlier centuries.

\section{REFERENCES}

1. Stephen Wiberley, "Journal Ranking from Citation Studies: A Comparison of National and Local Data from Social Work," Library Quarterly 52:348-59 (Oct. 1982).

2. Maurice B. Line, "On the Irrelevance of Citation Analysis to Practical Librarianship," in EURIM II: 
A European Conference on the Application of Research in Information Services and Libraries, ed. W. E. Batten (London: ASLIB, 1977), p.51-56.

3. Madeleine Stern, "Characteristics of the Literature of Literary Scholarship," College and Research Libraries 44:199-209 (July 1983).

4. R. Heinzkill, "Characteristics of References in Selected Scholarly English Literary Journals," Library Quarterly 50:352-65 (July 1980).

5. W. C. Simonton, "Characteristics of the Research Literature of the Fine Arts during the Period 1948-57," (Ph.D. diss., Univ. of Illinois, 1960).

6. D. L. Vaughan, "Characteristics of the Literature Cited by Authors in Articles in The Musical Quarterly, 1955-58, and The American Musicological Society Journal, 1953-56," (M.A. thesis, Univ. of North Carolina, 1959).

7. Karl J. Weintraub, "The Humanities Scholar and the Library," Library Quarterly 50:22-39 Jan. 1980).

8. C. Jones, M. Chapman, and P. C. Woods, "The Characteristics of the Literature Used by Historians," Journal of Librarianship 4:137-56 (July 1972).

9. David Baker, "Characteristics of the Literature Used by English Musicologists," Journal of Librarianship 10:182-209 (July 1978).

10. Stern, "Characteristics of the Literature," p.204.

11. Brian Harrison, "Emancipating Mistress and Maid," book review of Jane Lewis, Women in England 1870-1950 in TLS 4268:58 (Jan. 18, 1985).

12. Eugene Garfield, "Is Information Retrieval in the Arts and Humanities Inherently Different from That in Science?"' Library Quarterly 50:40-57 (Jan. 1980).

13. Derek J. De Solla Price, "Is Technology Historically Independent of Science? A Study in Statistical Historiography," Technology and Culture 6:553-68 (Fall 1965).

14. Charles B. Osburn, Academic Research and Library Resources: Changing Patterns in America (Westpor+ Conn.: Greenwood, 1979).

\section{You Are Invited to Attend 1500 Life Science Meetings ...Without Leaving Home}

In 1985, BIOSIS will greatly increase its already extensive coverage of the life science meeting literature - through BIOLOGICAL ABSTRACTS/RRM* (Reports, Reviews, Meetings).

Why? Because meeting papers often provide the first clues to important new research. And, as you've probably already discovered, finding these papers is getting harder and harder.'

In 1985 , we're going to alert you to more than 140,000 papers recently presented at major scientific conferences around the world. Papers important to research awareness. . . papers not reported anywhere else.

We thought you'd like to be the first to know.

For more information about BA/RRM, contact BIOSIS Product Planning \& Promotion Dept., 2100 Arch Street, Philadelphia, PA 19103-1399, USA, or call toll free (800) 523-4806 (USA, except AK, HI, PA). (215) 587-4800 worldwide. Telex 831739.

'If you're a regular reader of Nature, you've probably seen the letters in the Correspondence section in the past year on the importance of meeting papers. If you haven't, we'd like to share them with you. Write to BIOSIS User Services for a summary of the dialogue. 


\section{INTRODUCING INFORMATION EXPORTS FROM JAPAN.}

Japan has exported its products and technology for years. But it's been difficult to get the important information behind the technology, especially when it's only published in Japanese.

Now, Japan's technological information and research can be yours, with the Japanese Technical Information Service (JTIS) from University Microfilms International, UMI.

When you subscribe to Japanese Technical Abstracts (JTA), the first product offered by JTIS, you receive convenient abstracts in English every month from more than 750 Japanese publications. A wide variety of businesses and technologies are covered, including microelectronics, computer technology, biotechnology, aerospace engineering, business management, quality control, finance, deferise, ceramics, and many others.

Now you can become an expert on the latest information exports from Japan, simply by subscribing to JTIS. They could be the most important exports your company has ever acquired.

For more information about JTIS, see your corporate information specialist or call UMI. In the U.S., call toll-free 800-521-0600. In Michigan, Alaska and Hawaii, call collect 313-761-4700. In Canada, call toll-free 800-343-5299.

\section{JTIS \\ Ann Arbor, Michigan 48106 (313) $761-4700$}

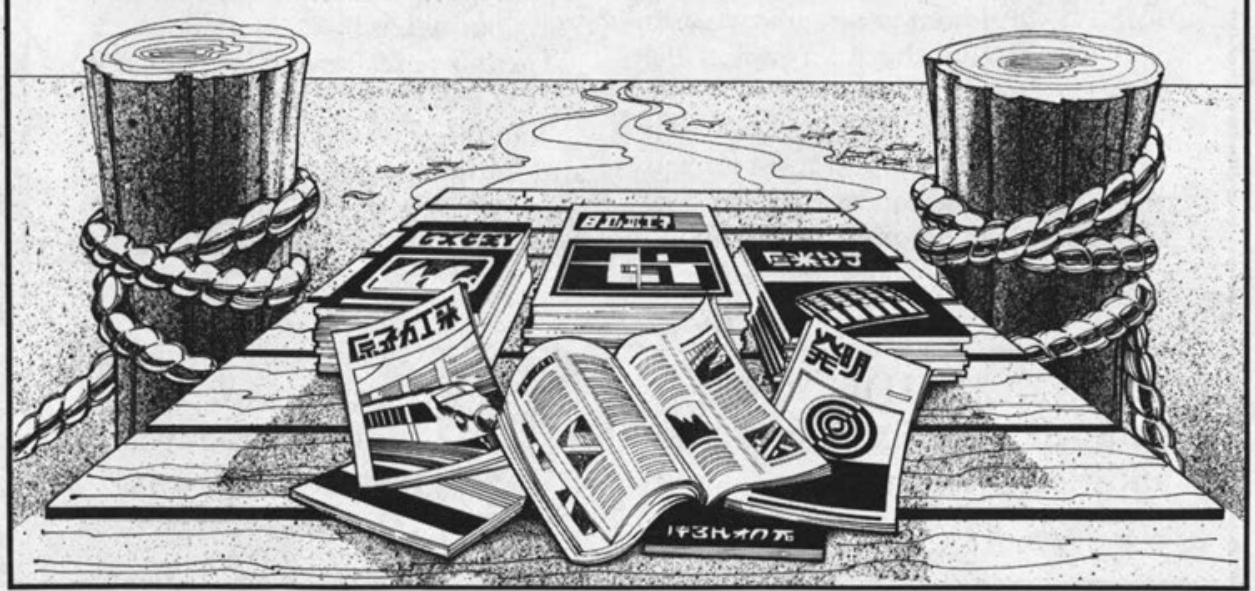




\section{Free Reference Service}

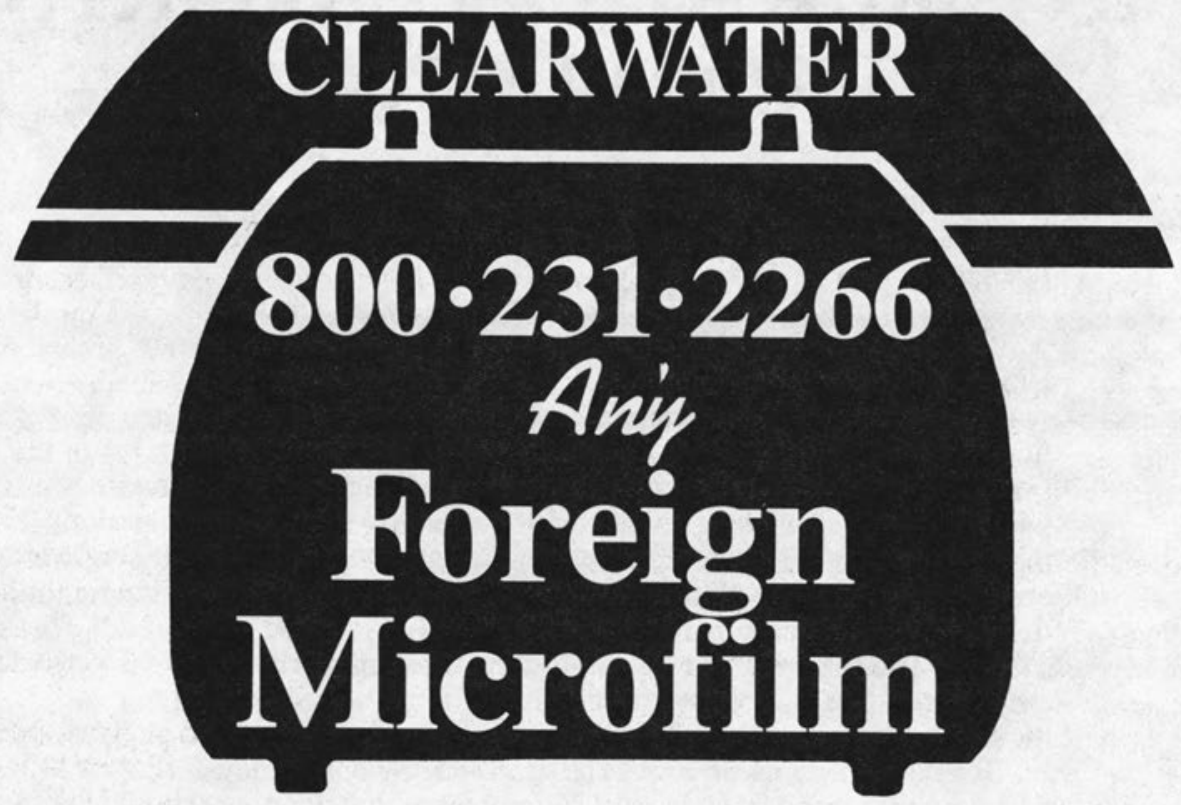

$\mathbf{H}$ eign serial? A rare botany collection? Illuminated manuscripts? Foreign government documents? Just call Clearwater Publishing, toll-free, at $800-231-2266$ and we will search it for you, at no charge. In many cases you will receive the information the same day.

Clearwater Publishing, North American distributor for most foreign micropublishers, can obtain any foreign microform for you, at the publisher's list price.

SPECIAL: IDC Orders shipped Air Express at no additional charge.
We:

- handle customs clearance

- thoroughly check all shipments

- assume responsibility for claims

- bill you at current exchange rates

- prepare invoices according to your needs

There is never any additional cost to you for these services.

You can always rely on courteous and prompt service when you call Clearwater, either to order a microform title or just for information.

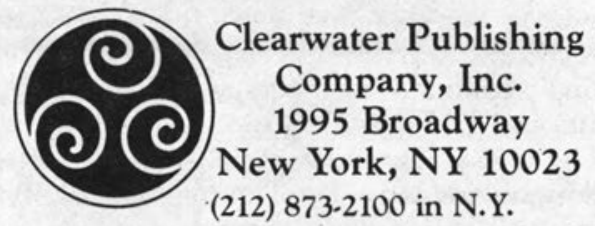

